University of Nebraska - Lincoln

DigitalCommons@University of Nebraska - Lincoln

Civil Engineering Faculty Publications

Civil Engineering

2016

Field-Scale Testing and Numerical Investigation of Soil-Boulder Interaction under Vehicular Impact Using FEM and Coupled FEM-SPH Formulations

Lynsey Reese

Pennsylvania State University

Tong Qiu

Pennsylvania State University, tuq1@psu.edu

Daniel Linzell

University of Nebraska-Lincoln, dlinzell@unl.edu

Zoltan Rado

Pennsylvania State University

Follow this and additional works at: http://digitalcommons.unl.edu/civilengfacpub

Part of the Civil Engineering Commons, Mechanics of Materials Commons, and the Transportation Engineering Commons

Reese, Lynsey; Qiu, Tong; Linzell, Daniel; and Rado, Zoltan, "Field-Scale Testing and Numerical Investigation of Soil-Boulder Interaction under Vehicular Impact Using FEM and Coupled FEM-SPH Formulations" (2016). Civil Engineering Faculty Publications. 143.

http://digitalcommons.unl.edu/civilengfacpub/143

This Article is brought to you for free and open access by the Civil Engineering at DigitalCommons@University of Nebraska - Lincoln. It has been accepted for inclusion in Civil Engineering Faculty Publications by an authorized administrator of DigitalCommons@University of Nebraska - Lincoln. 


\title{
Field-scale testing and numerical investigation of soil-boulder interaction under vehicular impact using FEM and coupled FEM-SPH formulations
}

\author{
Lynsey Reese', Tong Qiu', Daniel Linzell² \\ and Zoltan Rado'
}

\begin{abstract}
A computational approach that couples the Finite Element Method and the Smoothed Particle Hydrodynamics method may be advantageous for simulating the response of complex, physical systems involving large deformations. However, comparisons of this modeling technique against field-scale test data are remarkably sparse in literature. This study presents three field-scale tests involving vehicular impact into three landscape vehicular anti-ram barriers. Each barrier consisted of a single boulder embedded in compacted American Association of State Highway and Transportation Officials soil and physical testing resulted in one of the following outcomes: minimal boulder/soil movement (Test I), moderate boulder/soil movement (Test 2), and severe boulder/soil movement and vehicle override (Test 3). For each test, two LS-DYNA models were developed: a model using a traditional finite element method approach for the entire soil region along with a model using a hybrid finite element method-smoothed particle hydrodynamics approach where the near-field soil region was simulated using smoothed particle hydrodynamics. For Tests $I$ and 2, both the traditional finite element method approach and the hybrid finite element method-smoothed particle hydrodynamics approach were able to accurately match data collected from the field tests. However, for Test 3, the finite element method-only approach was not able to accurately predict the global response of the system under vehicular impact. On the other hand, the hybrid finite element method-smoothed particle hydrodynamics approach was able to capture global response of the system including boulder rotation, soil upheaval, and vehicle override.
\end{abstract}

\section{Keywords}

Anti-ram systems, boulder, crash tests, large deformations, numerical model, smoothed particle hydrodynamics method, soil-structure interaction

\footnotetext{
'Department of Civil and Environmental Engineering, The Pennsylvania State University, University Park, PA, USA ${ }^{2}$ Department of Civil Engineering, The University of Nebraska—Lincoln, Lincoln, NE, USA

Corresponding author:

Tong Qiu, Department of Civil and Environmental Engineering, The Pennsylvania State University, University Park, PA 16802, USA.

Email: tqiu@engr.psu.edu
} 


\section{Introduction}

Large deformation in geomaterials has been modeled using advanced elasto-plastic constitutive models and numerical techniques such as the finite element method (FEM) (Finn et al., 1986) and finite difference method (FDM) (Bathurst and Simac, 1994). Numerical models have the ability to capture the initiation and subsequent progressive deformation of geomaterials; however, the ability of these models to capture post-failure large deformation remains to be a critical issue. Since FEM and FDM are grid-based numerical methods, they generally have difficulty modeling large deformation of geomaterials. In FEM, each node of the computational mesh follows the assigned material during its motion. External surfaces and contact interfaces are easily tracked. Due to the fact that contact algorithms for the standard FEM are well-defined, this method has been the predominate one used for modeling geomaterials. The method fails when excessive distortions in elements cause spurious behaviors. Adaptive remeshing (Khoei and Lewis, 1999) and the Arbitrary LagrangianEulerian (ALE) method (Hughes et al., 1981) have been used to model large deformations in FEM. These remeshing techniques, however, are problematic when addressing highly distorted meshes, particularly when the material behavior is highly nonlinear (Belytschko et al., 2000). Particle-based, mesh-free methods were subsequently developed to handle these issues as a means of tracking materials using a set of interacting particles. Among these methods, the Smoothed Particle Hydrodynamics (SPH) method (Gingold and Monaghan, 1977; Lucy, 1977) has been shown to be a relatively mature and reliable method for accurately predicting large deformations of geomaterials.

SPH, a mesh-free method, is capable of handling large deformation without severe element distortion problems and has been used to model geomaterials post-failure (Bui et al., 2008; Chen and Qiu, 2012, 2014). Several researchers have successfully employed SPH to study the dynamic response of structures under high-velocity impact loads (Aktay et al., 2005; Jackson and Fuchs, 2008; Jankowiak and Lodygowski, 2013; Liu and Liu, 2003; Schwer, 2009; Swaddiwudhipong et al., 2010). This method is, however, usually less computationally efficient when compared to FEM and suffers from certain instability problems (Mohotti et al., 2015). Combining both approaches, using SPH to model the regions where large deformation is expected and using FEM elsewhere seems to be a logical application to address high-velocity impact with large soil deformations. Xu and Wang (2014) introduced different interactions methods available within LS-DYNA (Hallquist, 2013; Livermore Software Technology Company (LSTC), 2006) for SPH formulations and numerous researchers have incorporated a combined model of SPH and Langrangian formulations (Jankowiak and Lodygowski, 2013; Swaddiwudhipong et al., 2010; Thiyahuddin et al., 2012).

Landscape Vehicular Anti-Ram (LVAR) barriers play a crucial role in the protection of critical assets against terroristic threats. These barriers are designed to stop vehicular threats based on American Society for Testing and Materials (ASTM) F2656: Standard Test Method for Vehicle Crash Testing of Perimeter Barriers (ASTM, 2007) with a design criterion of P1 rating. P1 criterion indicates that the front edge of the truck bed cannot pass beyond 1 meter behind the inside edge of the barrier during an impact event. Because these barriers often comprise a single boulder embedded in compacted soil, the optimization of the boulder is an important aspect to keep the barrier economically feasible and installation procedures relatively simple. All of these barriers are designed and optimized using LS-DYNA before any full-scale testing commences, so it is imperative that the boulder and soil are modeled as accurately as possible to predict the translation and rotation of the boulder and the displacement of the soil during a vehicular impact. Inaccurately modeling the soil can lead to a false confidence in the barrier performance and result in failure to obtain a P1 rating of the barrier.

Several full-scale tests of single barriers embedded in soil with comparison to FEM have been published but lack to incorporate advanced modeling techniques like the addition of coupled FEM-SPH simulations. Asadollahi Pajouh et al. conducted full-scale tests and corresponding 
LS-DYNA simulations on a group of piles embedded in loose sand with no compaction. The fullscale test resulted in large soil deformations and the simulation over-predicted the pile deformation using traditional FEM analysis (Asadollahi Pajouh et al., 2014). Ren and Vesenjak investigated a crash analysis of road safety barriers using LS-DYNA and compared to a full-scale test. The LS-DYNA numerical model consisted of traditional FEM and used springs to represent the stiffness of the soil. From the analysis of the full-scale test, the posts embedded in soil showed large deformation as well as soil upheaval. However, analyzing the soil as spring elements does not allow the user to see the soil deformation post impact (Ren and Vesenjak, 2005). Wu and Thomson conducted full-scale tests and numerical simulations on a guardrail post and studied the interaction between the post and soil during quasi-static and dynamic loading. The guardrail was embedded in gravel and the authors used two different soil material models to represent the granular material. Simulations were conducted on quasi-static and dynamic loading conditions and both show severe element distortion in the soil elements near the guardrail. The authors also failed to show the comparison between full-scale tests and numerical analyses to assess the accuracy of the numerical models (Wu and Thomson, 2007).

Published comparisons between traditional FEM and coupled FEM-SPH simulations for soilstructure interaction involving large soil deformation are remarkably sparse in literature, particularly when this comparison is validated using instrumented, field-scale tests (Reese et al., 2012, 2014; Zhou et al., this issue). Keske et al. investigated a low-order modeling technique of vehicle impacts upon boulders embedded in cohesionless soil. The authors were able to predict the response of a large boulder with little soil movement using their low-order model compared to data collected from an instrumented field-scale test. However, a barrier system that exhibited large boulder translation and rotation as well as large soil deformation could not be accurately predicted using their low-order model (Keske et al., 2015). The need to use higher-order modeling techniques is required.

Research conducted at the Larson Transportation Institute, affiliated with The Pennsylvania State University, on the design and performance of three LVAR systems all consisting of a single boulder embedded in compacted fill will be summarized herein. Three field-scale tests were conducted and used to rate the performance of the barrier systems against M30 (vehicular speed of $48.3 \mathrm{~km} / \mathrm{hr}(30 \mathrm{mph})]$ impacts. Using high-speed cameras and field surveys, boulder movement was obtained from each test and was used to compare with model simulations. Each field-scale test was simulated using two LS-DYNA models. For the first model, the entire soil domain was modeled using traditional FEM formulation. For the second model, a coupled FEM-SPH formulation was used to model the soil domain, where SPH was used for the region near impact (large deformation was expected) and FEM was used to model regions beyond the impact zone. The optimal size of the SPH zone for accurate prediction of boulder translational and rotational movement (i.e. global response) was determined. A sensitivity study of SPH particle spacing was also conducted. In the following sections, the field-scale tests are first described followed by descriptions of the LS-DYNA models and selection of model parameters and formulations. Lastly, results and discussions on the capability of the LS-DYNA models for capturing global response of the LVAR systems are presented. This article focuses on the numerical predictions, including the use of FEM and coupled FEM-SPH formulations, and measured performance of LVAR systems in the field-scale tests. These results, therefore, provide a useful basis for evaluating predictive capabilities and limitations of the FEM and coupled FEM-SPH formulations in LS-DYNA when applied to LVAR barrier design.

\section{Field-scale testing}

Vehicular impact tests were completed according to ASTM F2656-07: Standard Test Method for Vehicle Crash Testing of Perimeter Barriers (ASTM, 2007), which establishes a penetration rating (desired P1) for perimeter barriers subjected to a vehicle impact (M30 designation). The test 


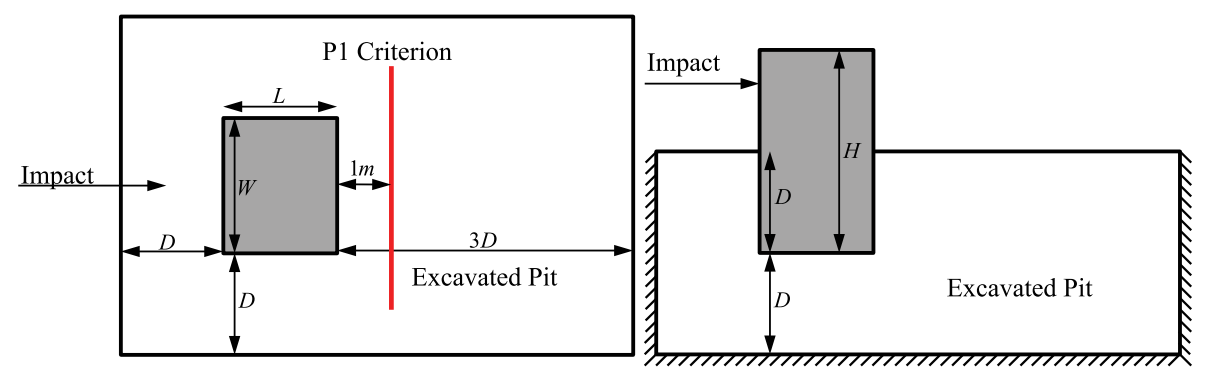

(a)

(b)

Figure I. General layout of boulder embedment: (a) plan view; and (b) elevation view (Dimension of excavated pit to scale, Dimension of boulder not to scale).

facility uses a rigid rail to provide vehicle guidance, a reverse towing system to accelerate the test vehicle to the required speed, and a release mechanism that disconnects the tow cable and steering guidance prior to impact. For a detailed description of the system, please refer to Reese et al. (2012, 2014).

\section{LVAR barriers}

Three different full-scale field tests were conducted for this research. Test 1 consisted of a Rockville White $(\mathrm{RW})$ granite boulder approximately $1.98 \mathrm{~m}$ wide $(\mathrm{W}) \times 1.68 \mathrm{~m}$ long $(\mathrm{L}) \times 3.43 \mathrm{~m}$ high $(\mathrm{H})$. The total embedment depth (D) was $2.03 \mathrm{~m}$. The approximate weight of the boulder was $27,200 \mathrm{~kg}$. Based on the information provided by the quarry that supplied the boulder, its bulk density and compressive strength were approximately $2696 \mathrm{~kg} / \mathrm{m}^{3}$ and $142 \mathrm{MPa}$, respectively (Coldspring Quarry, 2014). Test 2 consisted of an American Black (AB) granite boulder approximately $0.98 \mathrm{~m}$ $(\mathrm{W}) \times 1.05 \mathrm{~m}(\mathrm{~L}) \times 3.0 \mathrm{~m}(\mathrm{H})$. The total embedment depth (D) was $1.95 \mathrm{~m}$. The approximate weight was $9770 \mathrm{~kg}$. The bulk density and compressive strength of the boulder were approximately $3165 \mathrm{~kg} / \mathrm{m}^{3}$ and $300 \mathrm{MPa}$, respectively (Rock of Ages Quarry, 2015). Test 3 consisted of a different AB granite boulder approximately $1.19 \mathrm{~m}(\mathrm{~W}) \times 0.78 \mathrm{~m}(\mathrm{~L}) \times 2.44 \mathrm{~m}(\mathrm{H})$. The total embedment depth (D) was $1.38 \mathrm{~m}$. The approximate weight was $5580 \mathrm{~kg}$. Figure 1 summarizes the general dimensions for each of the tests described above. No natural fissures or joints were observed on the outer faces of the boulders. Along with material information provided from each quarry, small-scale testing, including uniaxial compression, split tension, Chevron bend, split Hopkinson pressure bar tests were completed to confirm supplied material property values (International Society for Rock Mechanics (ISRM), 2007; Reese et al., 2014; Xia et al., 2011). Table 1 summarizes the material properties of each of the granites used in the tests. Based on the tests conducted, an initial shear modulus of $9480 \mathrm{MPa}$ was determined, which is consistent with typical properties of granite published in literature (Gere and Timoshenko, 1984; Wyllie and Mah, 2004). Reese et al. conducted a single variant analysis to determine the sensitivity of the numerical simulation to the initial shear modulus $(G)$ of the Rockville White granite boulder, which demonstrated that the boulder displacement was relatively insensitive to the change of boulder stiffness (Reese et al., 2014).

According to ASTM F2656-07 standards, during the installation of each barrier, excavation should extend along the horizontal direction behind the boulder to a distance equal to 1.5 times the boulder embedment depth or $0.6 \mathrm{~m}$, whichever is greater up to a maximum of $1.8 \mathrm{~m}$ (ASTM, 2007). 
Table I. Summary of small-scale material testing on boulders.

\begin{tabular}{lccll}
\hline Granite type & $\begin{array}{l}\text { Compressive } \\
\text { strength }(\mathrm{MPa})\end{array}$ & $\begin{array}{l}\text { Tensile } \\
\text { strength }(\mathrm{MPa})\end{array}$ & $\begin{array}{l}\text { Fracture toughness } \\
\left(\mathrm{MN} / \mathrm{m}^{1.5}\right)\end{array}$ & $\begin{array}{l}\text { Split Hopkinson } \\
\text { pressure bar }(\mathrm{MPa})\end{array}$ \\
\hline Rockville White & $45.2 \pm 17.8$ & $7.4 \pm 0.8$ & $1.5 \pm 0.2$ & 133.1 \\
American Black & $168.2 \pm 38.6$ & $13.8 \pm 1.0$ & $2.5 \pm 0.3$ & 180.0 \\
\hline
\end{tabular}

As shown in Figure 1, this criterion is satisfied. Prior to each test, the extent of excavation was surveyed. Prior to boulder placement, an American Association of State Highway and Transportation Officials (AASHTO) uniformly graded coarse aggregate soil was placed into the excavated pit to the desired elevation in lifts of approximately $0.2 \mathrm{~m}$ and compacted using a tamping compactor to a density of not less than $90 \%$ maximum dry density in accordance with Test Method D6938-15 (ASTM, 2015). The aggregate used was $2 \mathrm{~B}$ gravel with a density of approximately $2100 \mathrm{~kg} / \mathrm{m}^{3}$, a porosity of approximately 0.35 , an elastic shear modulus of approximately $20 \mathrm{MPa}$, and a gradation in general accordance with AASHTO M147-65 specifications. The boulder was then lowered into the pit and centered for impact. Similar procedures were followed to backfill the pit with compacted aggregates.

\section{Test results}

High-speed cameras were implemented during testing to record pertinent information, such as boulder translation, displacement and rotation, and global response of the system, which included truck behavior. Figure 2 shows where the high-speed cameras were located to record the motions of the truck and boulder immediately prior to and after the impact. Camera 1 was positioned at a $90^{\circ}$ angle to the center of the test article to measure dynamic penetration. Camera 2 was positioned at a $90^{\circ}$ angle above the center of the test article to capture enough surface area prior to and after impact to determine impact speed, impact angle, exit angle, and debris field. Camera 3 was positioned behind the test article centered along the guidance rail to record the approach of the test vehicle to track its alignment with the center of the test article during impact. The distance from each camera to the center of the test article is summarized in Table 2. Each distance was used to calculate critical information from field-scale tests, including impact speed, angle of approach, truck dynamic penetration, and truck offset at impact.

Test 1 resulted in minimal movement (both translation and rotation) of the RW granite boulder. The front end of the truck rebounded after impact. Based on analysis of the high-speed video, the approach speed of the truck at impact was $52.3 \mathrm{~km} / \mathrm{h}$. Analysis of data from Camera 3 determined the centerline of the truck impacted the test article $14 \mathrm{~cm}$ to the left (to the side of Camera 1) of the critical impact point that was defined as the centerline of the boulder. Test 2 resulted in moderate boulder translation and rotation as well as soil upheaval behind the boulder during impact. From high-speed video analysis, the approach speed of the truck was $48.3 \mathrm{~km} / \mathrm{h}$ and the center of the truck impacted $6.57 \mathrm{~cm}$ to the right of the center of the $\mathrm{AB}$ boulder. During Test 3 vehicle impact, the $\mathrm{AB}$ granite boulder translated and rotated out of the ground upon impact. The truck ramped over the flipped boulder and landed with the back axle sitting on top of the boulder. During this test, a malfunction of the high-speed video trigger resulted in recording post-test data and not the actual impact. Based on the stationary radar system (Stalker Speed Sensor (S3)), the approach speed at impact was $54.7 \mathrm{~km} / \mathrm{h}$. This system determines the test vehicle speed during the towing process using a stationary Doppler radar speed sensor operating at a frequency of $34.7 \mathrm{GHz}$ and communicating through a RS-232 port (Stalker Traffic Technologies, 2014). Inspection after each 


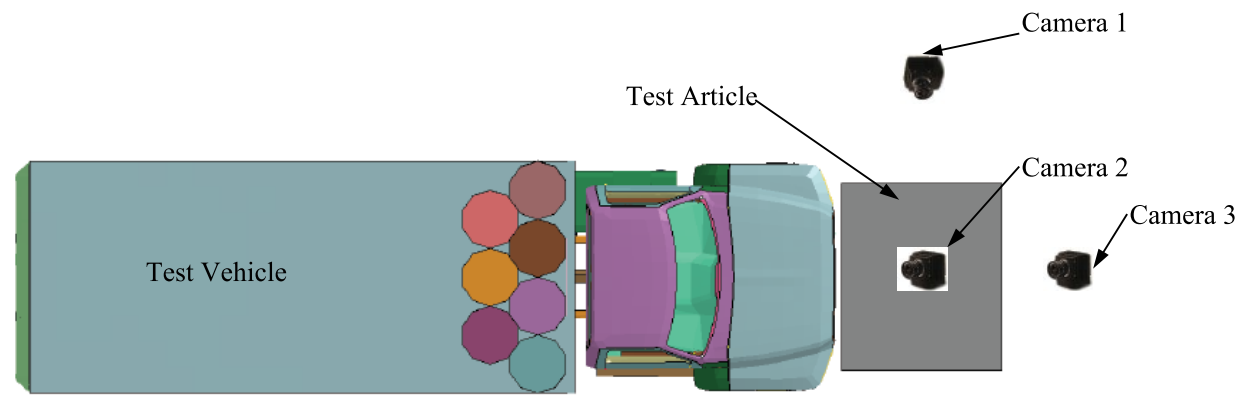

Figure 2. Location of high-speed video cameras in field-scale tests (not to scale).

Table 2. Distance from center of test article to each camera.

\begin{tabular}{llcl}
\hline & Camera I $(\mathrm{m})$ & Camera 2 $(\mathrm{m})$ & Camera 3 $(\mathrm{m})$ \\
\hline Test I & 20.55 & 15.94 & 32.31 \\
Test 2 & 25.04 & 6.76 & 23.06 \\
Test 3 & 20.57 & 15.77 & 30.56 \\
\hline
\end{tabular}

impact showed that none of the boulders showed any signs of fracture or cracking. Figure 3 shows the final position of the boulder and truck for each completed test. In particular, Figure 3(c) shows the truck override and boulder displacement due to the vehicle impact.

\section{LS-DYNA model}

The LS-DYNA research/commercial code (Hallquist, 2013; LSTC, 2006) was utilized to perform simulations to model the vehicular impact tests. In this section, the numerical model is first discussed, including a detailed description of SPH formulation as well as the constitutive model used, followed by a description of contact algorithms used within LS-DYNA to connect SPH particles to FEM segments.

\section{Numerical model}

Two numerical models of each field-scale test were created to compare their performance at capturing global response of the LVAR system when varying magnitudes of soil deformation occurred. The first model consisted solely of finite elements for the LVAR barrier and soil domain as shown in Figure 4(a), whereas the second model used a hybrid approach for modeling soil. In the near-field soil region, SPH particles were used, while solid finite elements were used in the far-field, as seen in Figure 4(b), to take advantage of SPH's capabilities in modeling large deformations and FEM's computational efficiency. Each model consisted of two parts: (1) medium-duty truck and (2) LVAR barrier consisting of a boulder embedded in soil.

The truck model used for the simulations was modified from a model readily available in the National Crash Analysis Center (NCAC) database (Mohan et al., 2003; National Crash Analysis Center (NCAC), 2008). The NCAC truck model was developed to ensure that the load transfer 


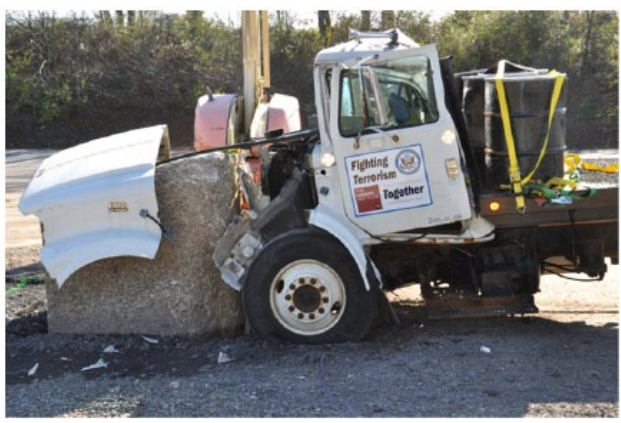

(a)

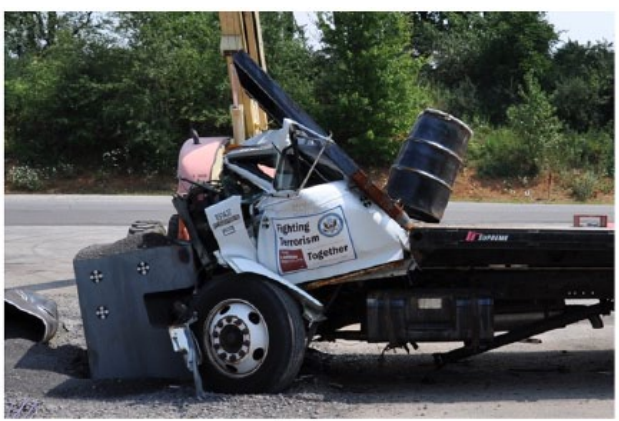

(b)

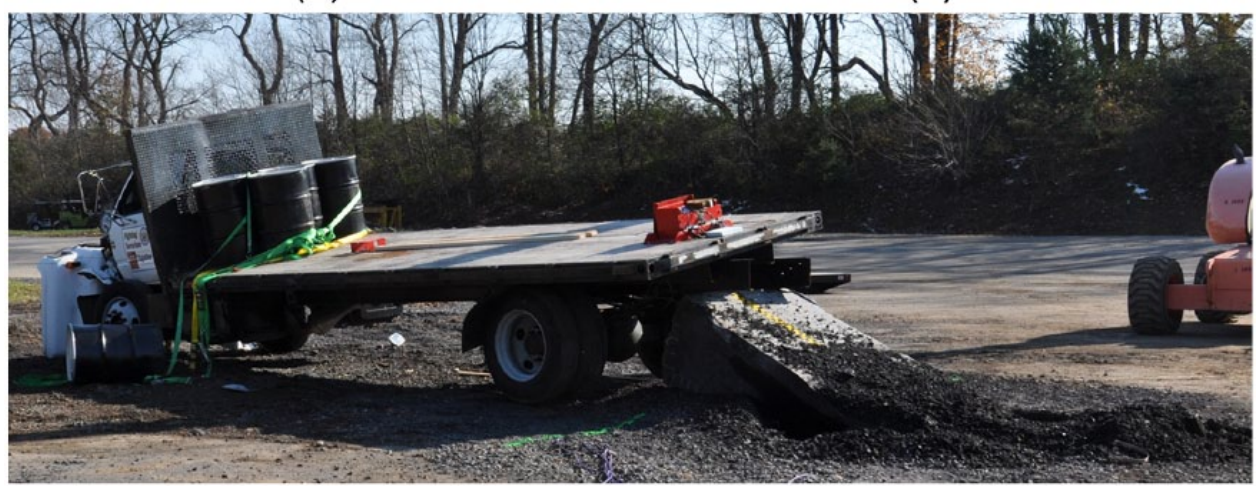

(c)

Figure 3. Final position of boulder and truck after impact for: (a) Test I, (b) Test 2, and (c) Test 3.

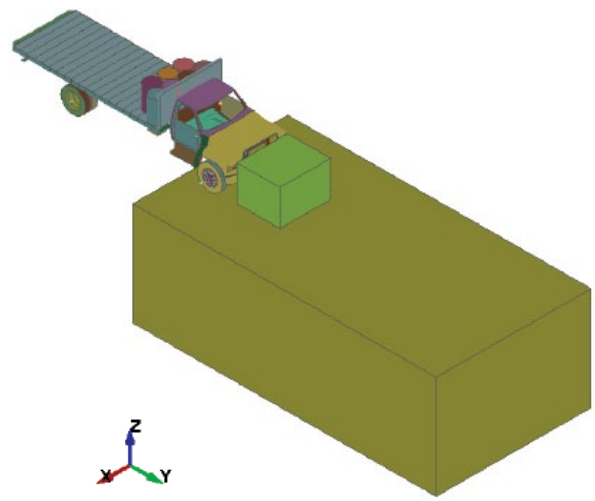

(a)

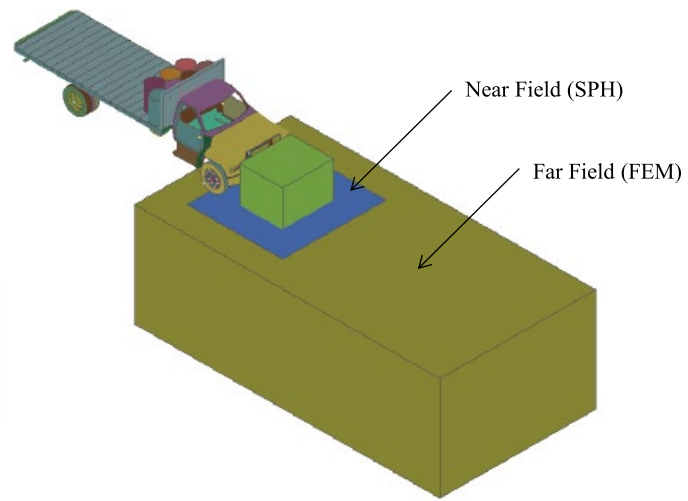

(b)

Figure 4. LS-DYNA models: (a) FEM-only model and (b) hybrid FEM-SPH model.

between the truck and hardware, the deformation of the truck, and the overall behavior of the truck during impact simulations would be as accurate as feasible, given model computational requirements. Based on requirements from ASTM F2656-07, the modified truck model consisted of 1606 
eight-node constant-stress solid elements, 20,333 four-node Belytschko-Tsay shell elements, and 377 Hughes-Liu beam elements with cross-section integration. The truck model was validated as reported in Reese et al. (2014) using checks of equilibrium, conservation of energy principles, and the amount of energy absorption that occurred through plastic deformation of truck components when hitting a rigid wall.

Each LVAR device comprised of a single boulder embedded in compacted AASHTO soil as shown in Figure 4. Eight-node constant-stress cubic solid elements were used for the boulder in both of the models. The solid element size was $100 \mathrm{~mm}$ based on Reese et al. (2014). The soil domain, representing an AASHTO uniformly graded coarse aggregate, was modeled using two different approaches. In the FEM-only model, eight-node constant-stress solid elements were used and varied in size from $75 \mathrm{~mm}$ near the boulder to $250 \mathrm{~mm}$ at the exterior of the soil domain. A mesh convergence study was conducted in Reese et al. (2014) for the FEM-only model by changing the mesh size nearest the boulder and transitioning to the exterior the soil domain. The mesh distribution described previously resulted in convergence of the mesh (Reese et al., 2014). The hybrid approach used a combination of SPH particles near the boulder connected to eightnode constant-stress solid elements in the far-field as seen in Figure 4(b). Based on SPH model parameters discussed in the subsequent sections, the size of the FEM elements (for the hybrid approach) were constant at $150 \mathrm{~mm}$. Detailed discussion of SPH formulation and model parameters of the hybrid approach are presented in subsequent sections. The extent of the soil domain, based on embedment depth of the boulder, remained the same between models and can be seen in Figure 1 (Reese et al., 2014).

The size of the soil domain was selected to negate any boundary effects from reflected compression waves that would interfere with the impact response. Normal translation of the exterior and bottom boundaries of the soil domain were the only constrained degrees of freedom. An investigation of the size of the soil domain, to negate any boundary effects, was conducted by changing the size of the soil domain (based on the embedment depth) and compares the barrier response for Test 1 . Four domain sizes were investigated: $2 \mathrm{D}-1 / 2$ embedment depth in the front and sides of the boulder and two times the embedment depth behind the boulder; 3D — one embedment depth in the front and sides and three times the embedment depth behind the boulder; 4D-3/2 embedment depth in the front and sides and four times the embedment depth behind the boulder; and 5D - two times the embedment depth on the sides and front of boulder and five times behind the boulder. The translational displacement of the top corner (furthest point from impact) of the boulder was monitored for convergence of the soil domain. Figure 5 shows displacement of the boulder while varying the soil domain. There was a 5.3 percent change when expanding the soil domain from $2 \mathrm{D}$ to $3 \mathrm{D}$, a 6.4 percent change when expanding from $3 \mathrm{D}$ to $4 \mathrm{D}$, and a 1.6 percent change when expanding from 4D to 5D. Therefore, based on this analysis, a soil domain of $3 / 2$ times the embedment depth around the front and sides of the boulder and four times the embedment depth behind the boulder is used for all subsequent analyses.

\section{SPH formulations for soil}

SPH is a mesh-free, Langrangian, particle-based method developed by Lucy (1977) and Gingold and Monaghan (1977). In SPH simulations, the computational domain is discretized into a finite number of particles, each representing a certain volume and mass of the material (fluid or solid) and carrying field variables such as velocity, acceleration, density, and pressure/stress. Therefore, the SPH method is a continuum-scale numerical method. The material properties, $\Pi^{h} f(x)$, at any point $x$ in the simulation domain are then calculated according to an interpolation process over its neighboring particles that are within its influence domain $\Omega$ through 


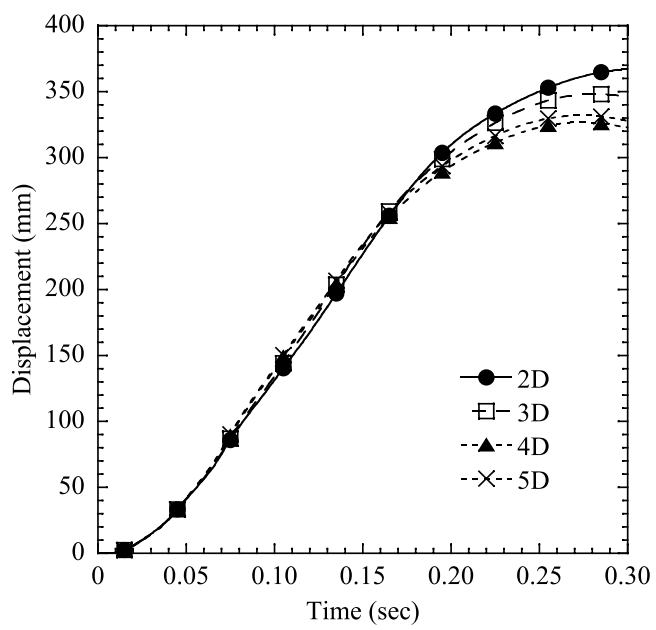

Figure 5. Effect of soil domain size on simulated boulder displacement for Test I.

$$
\Pi^{h} f(x)=\int_{\Omega} f(y) W(x-y, h) d y
$$

where $W$ is the smoothing kernel function, which is a weighting function and $h$ is the smoothing length that is a unit measure of the sub-domain of influence of function $W$. Figure 6 illustrates the underlying principle behind the interpolation process.

The kernel function $W$ is defined using a function $\theta$ by the relation

$$
W(x, h)=\frac{1}{h(x)^{d}} \theta(x)
$$

where $d$ is the number of space dimensions. It should be noted that $W(x, h)$ should be a centrally peaked function. The most common smoothing kernel is the cubic B-spline which is defined as

$$
\theta(u)=C \times\left\{\begin{array}{ll}
1-1.5 u^{2}+0.75 u^{3} & |u| \leqslant 1 \\
0.25 \times(2-u)^{3} & 1 \leqslant|u| \leqslant 2 \\
0 & |u| \geqslant 2
\end{array}\right\}
$$

where $C$ is a constant of normalization that depends on the number of space dimensions.

LS-DYNA computes the initial smoothing length, $h_{0}$, for each SPH part by taking the maximum of the minimum distance between every particle. Every particle has its own smoothing length which varies in time according to the following equation

$$
\frac{d}{d t}[h(t)]=h(t) \nabla \cdot v
$$

where $h(t)$ is the smoothing length and $\nabla \cdot v$ is the divergence of flow. The smoothing length increases when particles separate from each other and reduces when the concentration of particles 


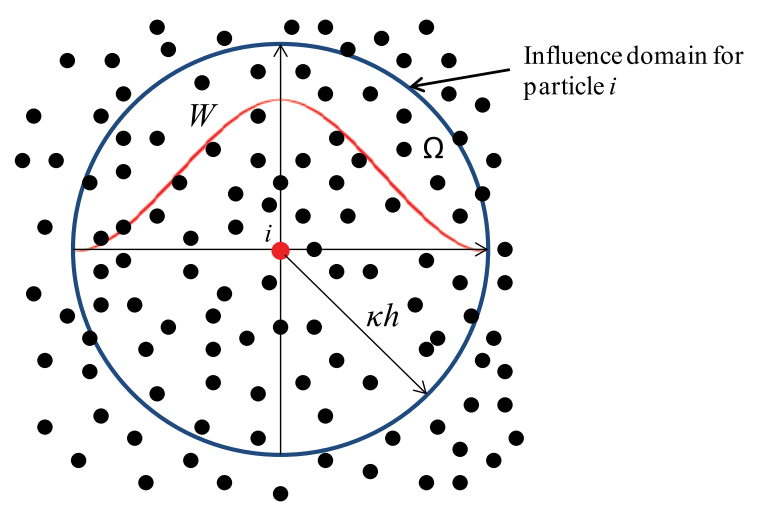

Figure 6. Particle approximation based on kernel function $W$ in influence domain $\Omega$ with radius kh.

increases. It varies to keep the same number of particles in the neighborhood. The smoothing length varies between the minimum and maximum values

$$
H M I N \times h_{0}<h(t)<H M A X \times h_{0}
$$

where $H M I N$ and HMAX are scale factors for the smoothing length. The smoothing length has significant impacts on the overall numerical behavior (e.g. accuracy and efficiency). SPH particles interact with each other only if they are within each other's influence domain; otherwise, they are independent from each other as shown in Figure 6. Therefore, larger smoothing length (i.e. larger influence domain) generally results in smoother or more continuous behavior as the SPH particles are more interdependent; whereas smaller smoothing length generally yields more discrete behaviors as the SPH particles are more independent from each other. Since the smoothing length is a function of the individual particle and time, the constant applied (i.e. $\kappa$ in Figure 6 ) to the smoothing length is an important parameter. Sakakibara et al. (2008) recommends using a smoothing constant of 1.05 instead of the recommended value of 1.2 from LS-DYNA. This research compared FEM and SPH simulation of the same model and varied several different SPH parameters, including particle spacing, smoothing length constant, and effect of renormalization in an attempt to determine the most efficient and accurate combination of SPH parameters. These studies will be discussed later in this article.

\section{Material properties}

The LS-DYNA Material Type 173, "Mohr-Coulomb (M-C)" (Hallquist, 2013) was utilized to model the boulder and soil behavior in all the simulations. The M-C model was used to represent the soil and boulder due to its ability to effectively and simplistically capture impact conditions present in the field testing (Reese et al., 2014). The Mohr-Coulomb model characterizes failure of a material based on its cohesion, friction angle, and normal and shear stresses at a point as follows (Hallquist, 2013; LSTC, 2006)

$$
\tau_{\max }=c+\sigma_{n} \tan (\phi)
$$

where $\tau_{\max }$ is the shear strength on any plane, $\sigma_{n}$ is the normal stress on that plane, $C$ is cohesion, and $\phi$ is the friction angle. Model parameters for the boulder and soil were calibrated and validated 
Table 3. Summary of boulder and soil parameters used in simulations.

\begin{tabular}{llllllc}
\hline & $\begin{array}{l}\text { Density } \\
\left.\text { (ton } / \mathrm{mm}^{3}\right)\end{array}$ & $\begin{array}{l}\text { Elastic shear } \\
\text { modulus }(\mathrm{MPa})\end{array}$ & $\begin{array}{l}\text { Poisson's } \\
\text { ratio }\end{array}$ & $\begin{array}{l}\text { Friction angle } \\
\text { (degrees) }\end{array}$ & $\begin{array}{l}\text { Cohesion } \\
(\mathrm{MPa})\end{array}$ & $\begin{array}{l}\text { Dilation angle } \\
\text { (degrees) }\end{array}$ \\
\hline Boulder & $\begin{array}{l}3.056 \times 10^{-9} \\
\text { Soil }\end{array}$ & 9480 & 0.25 & 37.8 & 18.3 & 0 \\
\hline
\end{tabular}

in Reese et al. (2014) and material properties are summarized in Table 3. Although different boulders were used in these three tests, the boulders behaved essentially as a rigid mass and, hence, the same boulder properties were used for all numerical simulations. This approach is justified by Reese et al. (2014).

\section{FEM-SPH coupling}

Both SPH and FEM formulations in LS-DYNA are based on the Lagrangian approach. Therefore, it is possible to link both methods at an interface. The interface ensures continuous coupling of the two methods. At the interface, the SPH particles are constrained and move with the elements. The influence domain of the particles at/near the interface zone, such as that of the particle $i$ (see Figure 7), covers both the FE mesh and SPH particles and certain considerations are required in the computation. For strain and strain rate calculation of each particle, only those from the SPH particles within the influence domain are considered, whereas the contributions from both SPH particles and elements inside the influence domain are included to calculate forces (Johnson, 1994; LSTC, 2006).

LS-DYNA allows mesh-based and mesh-free techniques, such as SPH, to exist and interact in one simulation, thereby allowing users to take advantage of both procedures. The interaction or coupling between SPH particles and FEM elements can be defined using traditional tied- or penaltybased contact definitions (Beal et al., 2013). Since there is no mesh connectivity for the SPH particles, it is imperative that only "nodes_to_surface" contact definitions are utilized in which SPH is always defined to be the slave node $\left(n_{s}\right)$ and finite elements are defined to be the master surface.

Tied-based contact consists of "tying" SPH slave nodes to FEM surfaces to connect the two domains. LS-DYNA ties translational degrees of freedom of nodes to a specified surface. The constraints are only imposed on the slave nodes, so the more coarsely meshed side of the interface should be the master surfaces (i.e. FEM) (LSTC, 2006). Ideally, each master node should coincide with a slave node to ensure complete displacement compatibility along the interface, but this is difficult, if not impossible, to achieve.

Penalty-based contact consists of placing normal interface springs, stiffness factor equal to $k_{i}$, between all penetrating nodes and the contact surface. Standard penalty formulation was utilized for this study. In standard penalty formulation, the interface stiffness is chosen to be approximately the same order of magnitude as the stiffness of the interface element normal to the interface particle. In applying the penalty method, each slave node is checked for penetration through the master surface. If the slave node does not penetrate, contact force is not applied. If it does penetrate, the contact force is calculated based on the amount of penetration and contact stiffness, which is then applied to the slave node and contact point (LSTC, 2006).

The stiffness factor, $k_{i}$, is determined in several ways including: the minimum of the master segment and slave node stiffness, the master segment stiffness, the slave node stiffness, or the area-/mass-weighted slave node value. Since the boundary between SPH particles and solid FEM segments is the same material with identical stiffness, a minimum of the master segment and slave node stiffness was used. 


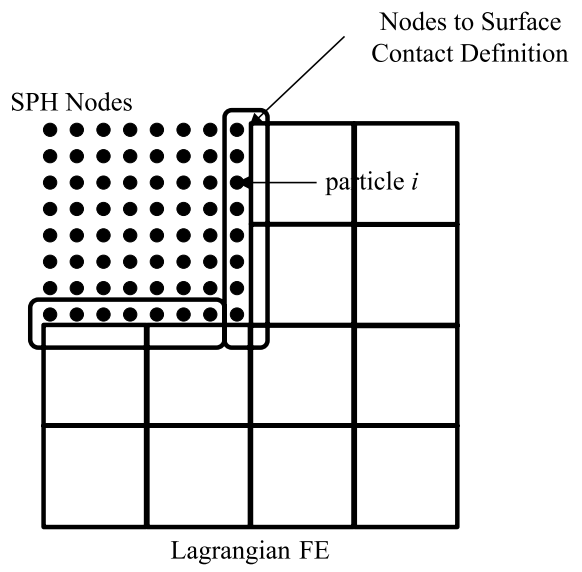

Figure 7. Connection between SPH nodes and Lagrangian FE mesh.

Penalty-based automatic "nodes-to-surface" contact was used for each interface with SPH particles including: boulder and FEM soil domain. The contact between the boulder and SPH soil domain used a static and dynamic coefficient of friction of 0.414 determined by the friction angle of the AASHTO soil. The static and dynamic coefficient of friction for the SPH and FEM soil domain was 1.0. Figure 7 displays the contact between the SPH nodes and the surface of the FE model. The SPH nodes are always the slave while the finite elements are always the master surface.

\section{Model parameters}

Several parameters affect the overall response of the near-field soil region simulated using SPH particles, including particle spacing, type of formulation, smoothing length, and size of the region. Small-scale SPH simulations were conducted to determine the particle spacing. The formulation type and smoothing length were determined from literature and discussed below. These small-scale SPH simulations were then compared to a model comprising Lagrangian finite elements to determine the accuracy of the SPH model. Lastly, Test 3 was used to determine the appropriate extent of the near-field SPH soil region needed to accurately predict the behavior resulting from large soil deformations exhibited in the field-scale test.

\section{SPH particle spacing}

Particle spacing plays an integral role in accurately predicting the overall response of the system as well as enhancing model computational efficiency. An increase in particle spacing decreases computational time but decreases model accuracy. It is generally recommended for a model to have densely packed SPH particles with a constant initial distance between them in all directions (Bojanowski, 2014; Bojanowski and Kulak, 2010; Kulak and Schwer, 2012). It is also recommended for stability of the calculations to have at least four SPH particles per face of the Lagrangian element in contact with those SPH particles.

A small-scale numerical study was conducted to investigate the optimal SPH spacing for contact between SPH and FEM domains. This small-scale study consisted of a confined compression 


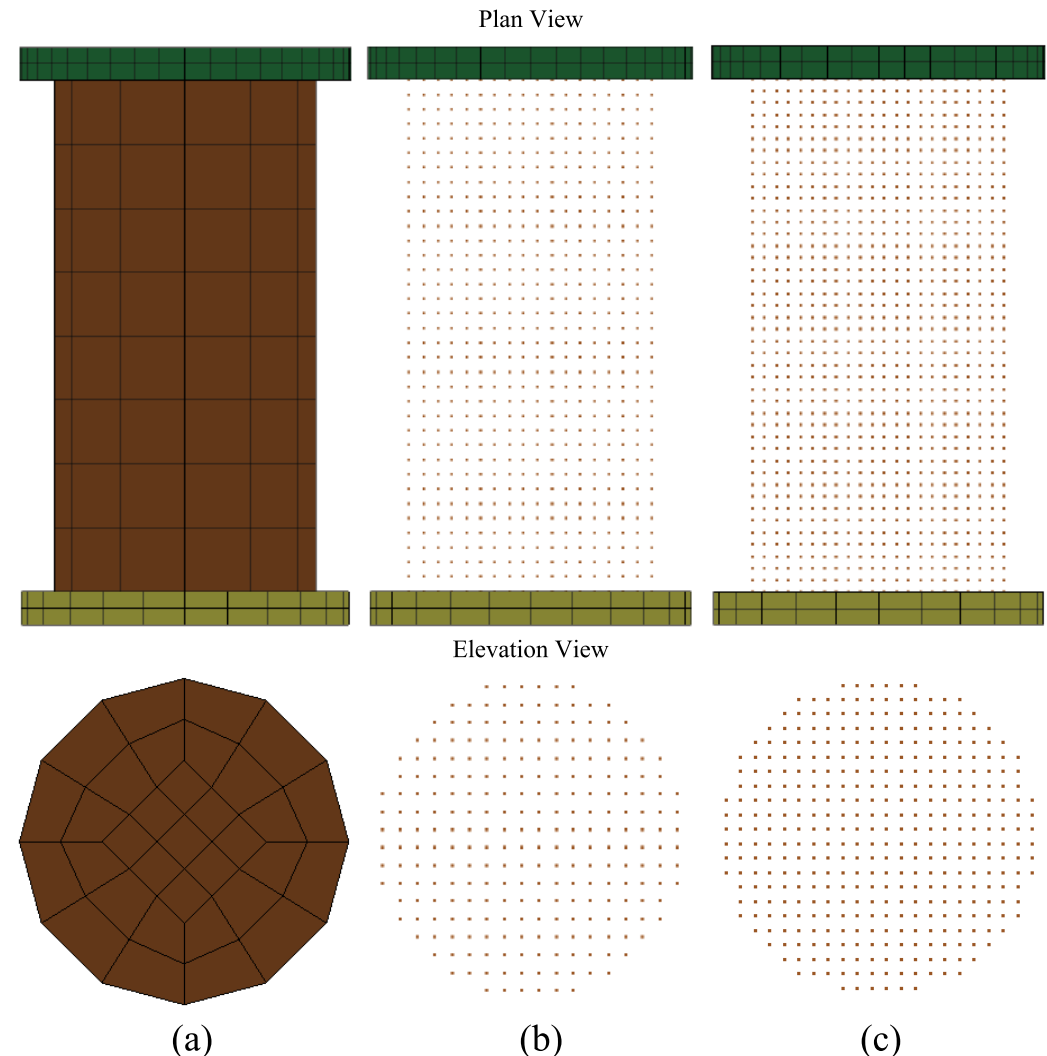

(a)

(b)

(c)

Figure 8. Plan and elevation view of small-scale confined compression test using: (a) finite elements: $25.4 \mathrm{~mm}$; (b) SPH particles: $4 \times 4$ configuration; and (c) SPH particles: $5 \times 5$ configuration.

test of soil as shown in Figure 8. The test was simulated using two formulations: a FEM-only model where the top loading ram, confinement cylinder, base and soil were modeled using traditional FEM formulations, and a coupled FEM-SPH model where the soil was modeled using SPH formulations. Soil properties were from Reese et al. (2014). In the numerical simulations, the loading ram moved vertically and the displacement and reaction force from the soil were tracked. Element sizes of 18.4 and $25.4 \mathrm{~mm}$ were used for the FEM models and showed convergence as seen in Figure 9. Based on the larger element size, the SPH model was created using four SPH nodes per element side (a four-by-four configuration) as seen in Figure 8(b) and five nodes per element side (a five-by-five configuration) as shown in Figure 8(c). The simulated force versus displacement curves from the SPH is shown in Figure 9 for the four-by-four and five-by-five SPH arrangements. There is a good agreement and convergence between the FEM and the five-by-five SPH arrangement. The four-by-four arrangement did not converge with the FEM model, mostly likely due to the insufficient number of particles per FEM mesh. From this comparative analysis, a grid of five-by-five SPH particles was used where SPH particles were in contact with a FEM domain. 


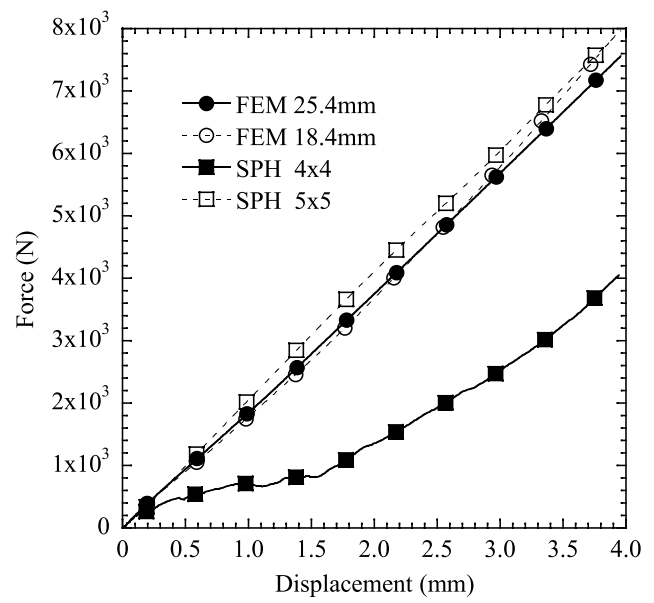

Figure 9. Force versus displacement for FEM and FEM-SPH models.

\section{Formulation and smoothing length}

There are several types of SPH formulations within LS-DYNA that determine particle approximation, including a default formulation and a renormalization approximation. Sakakibara et al. (2008) conducted analyses of the effects of changing formulation type while keeping the smoothing length constant. Based on the analysis using the default formulation, the particles at the boundary edge had lower stress due to a truncated boundary and reduced number of particles within each edge particle's influence domain. To account for the issue of the FEM mesh truncating the influence domain of SPH particles in the vicinity of a FEM-SPH boundary, the renormalization technique readily available in LS-DYNA proved to correct the stress inaccuracies. Therefore, renormalization approximation (FORM 1) was used for all SPH analyses in this study.

Smoothing length is another SPH parameter that directly affects the influence domain of the particles. The smoothing length constant can be varied between recommended values of 1.05 and 1.3 within LS-DYNA. Comparisons of four different SPH models with increasing particle density were analyzed to see the effects of varying the smoothing length constant. Three smoothing lengths (1.05, 1.2 (default), and 1.3) were examined (Sakakibara et al., 2008). A smoothing length constant of 1.05 was found to be the most accurate in all models regardless of the particle density. In all cases, a higher smoothing length caused a weaker response of the model and material was less stiff. Based on this analysis, a smoothing length constant of 1.05 was used in all subsequent analyses.

\section{Near-field SPH soil region}

Based on the above parameters, the extent of the near-field SPH soil region was determined as a function of the embedment depth of the barrier based on observations seen for Test 3 and shown in Figure 3(c). Using an entire soil domain consisting of SPH would not be computationally efficient and Reese et al. (2014) showed regions of little soil disturbance could be accurately predicted using traditional FEM formulations. Therefore, three different near-field SPH soil domains, based on Test 3 as described in a previous section, were constructed based on a proportion of the embedment depth of the barrier $(1 / 4,1 / 2$, and $3 / 4)$ as shown in Figure 10(a) to (c). The SPH regions were located around the boulder where large soil deformation was expected. Each model was compared to the 


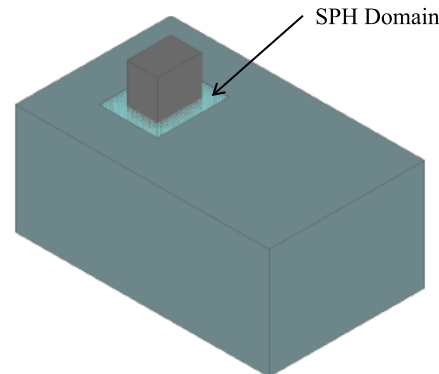

(a)

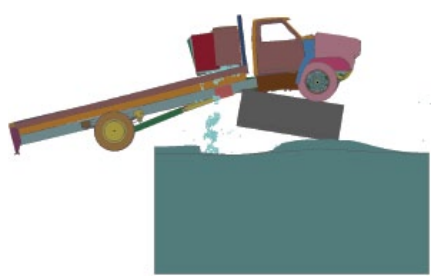

(d)

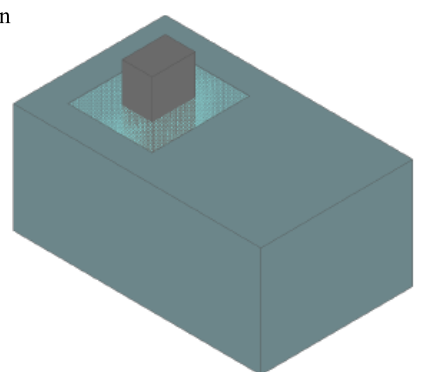

(b)

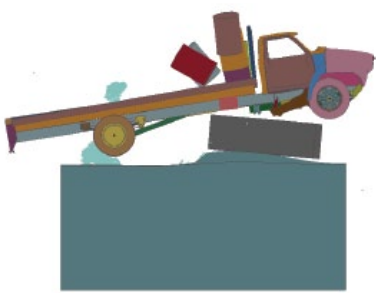

(e)

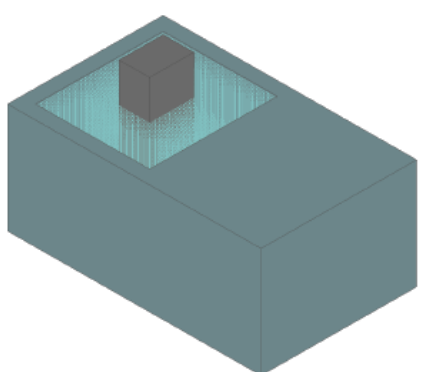

(c)

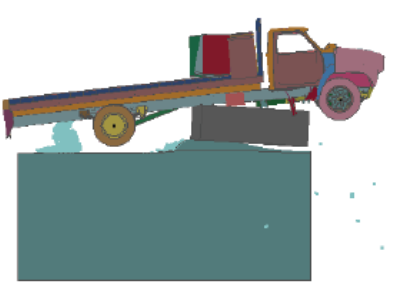

(f)

Figure 10. Extent of near-field SPH soil domain for Test 3: (a) $1 / 4$ embedment depth; (b) $1 / 2$ embedment depth; (c) $3 / 4$ embedment depth; post impact condition for: (d) 1/4 embedment depth; (e) 1/2 embedment depth; and (f) $3 / 4$ embedment depth.

final boulder/truck position (Figure 3(c)) to determine the extent of the near-field SPH soil region that most accurately predicted the response. Figure 10(d) shows the final resting position of the truck and boulder for a SPH region extending $1 / 4$ of the embedment depth of the boulder. The computational time for this analysis was $3 \mathrm{~h} 42 \mathrm{~min}$. Figure 10 (e) shows the corresponding plot for a SPH region equal to $1 / 2$ of the embedment depth away from the boulder and its computational time was $5 \mathrm{~h} 44 \mathrm{~min}$. Figure $10(\mathrm{f})$ shows the corresponding plot for a SPH region equal to $3 / 4$ of the embedment depth away from the boulder and its computational time was $12 \mathrm{~h} 8 \mathrm{~min}$. Analyzing the distance the truck traveled past the boulder was used as a basis to determine which SPH soil domain size to use. By visual inspection, the $1 / 4$ embedment depth model does not accurately predict the final position of the truck ramping over the boulder. The boulder sticks to the bottom of the truck and digs into the FEM soil domain causing the truck to stop short of ramping entirely over the boulder. In the $1 / 2$ embedment depth model, the truck traveled $2210 \mathrm{~mm}$ farther than the $1 / 4$ embedment depth model and more accurately predicts the final position of the truck. The $3 / 4$ embedment depth model shows the truck traveled approximately $540 \mathrm{~mm}$ farther than the $1 / 2$ embedment model. Both the $1 / 2$ and $3 / 4$ embedment depth models capture the overall behavior of Test 3 with little quantitative difference in results, but a dramatic difference in computational efficiency. The $3 / 4$ embedment depth model takes over two times the computational time for little difference in results. Therefore, the $1 / 2$ embedment depth model is used to represent the near-field SPH soil region.

\section{Results and discussion}

The final position of the truck after impact from Tests 1,2, and 3 and snapshots of their respective LS-DYNA simulations using FEM-only and hybrid FEM-SPH formulations are shown in 
(a)
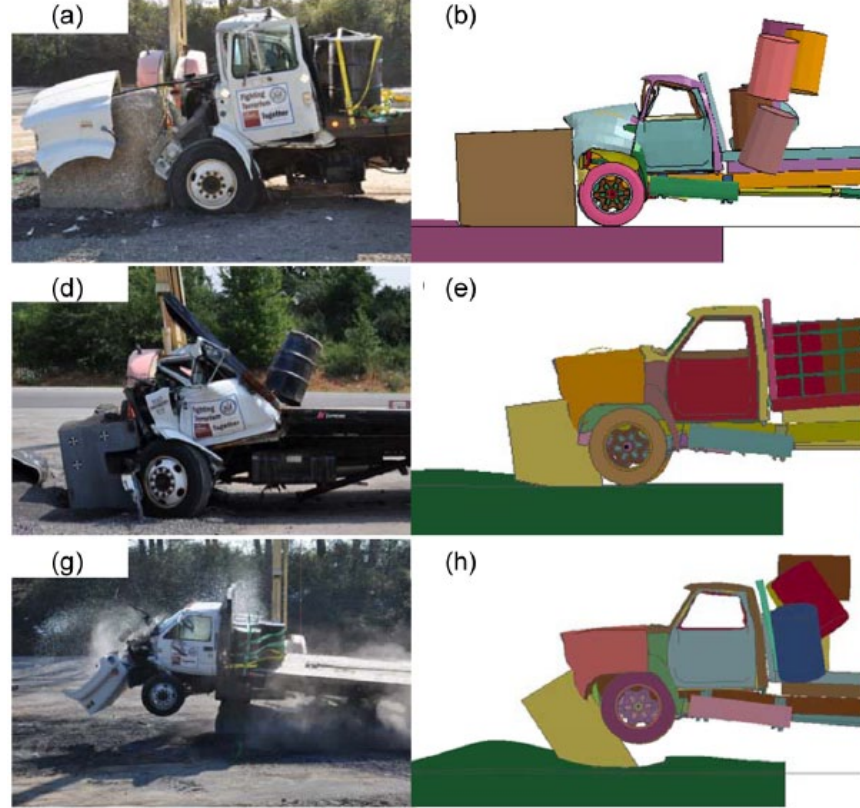

(e)

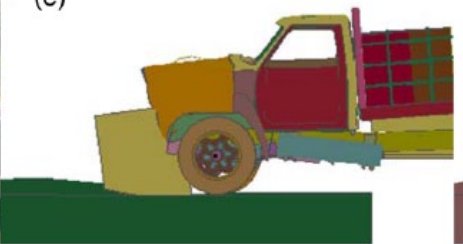

(h)

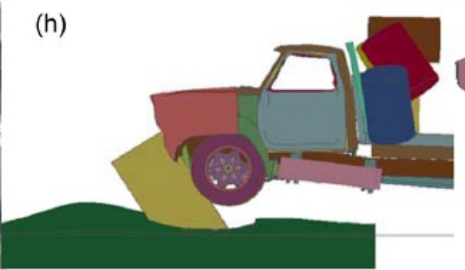

(c)

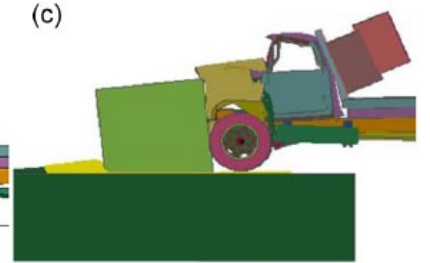

(f)
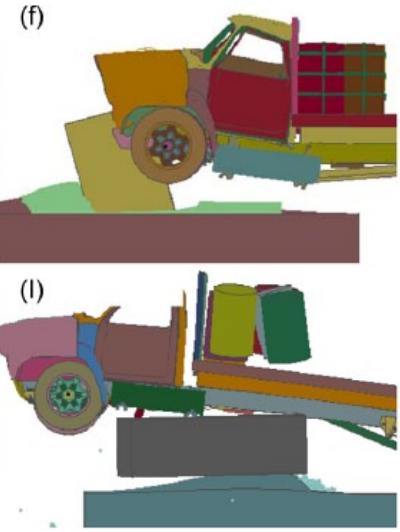

Figure I I. Comparison of final impact condition of field-scale tests and LS-DYNA simulations: (a) Test I, (b) FEM Test I, (c) hybrid Test I, (d) Test 2, (e) FEM Test 2, (f) hybrid Test 2, (g) Test 3, (h) FEM Test 3, and (i) hybrid Test 3.

Figure 11. From this qualitative comparison, Test 1 showed a good agreement between the fieldscale test and both of the LS-DYNA models. Test 2 showed a similarly good agreement between the field-scale test and the LS-DYNA models, but the hybrid model showed slight truck ramping that was not present in the FEM model or the field-scale test. The largest qualitative difference between LS-DYNA models was for Test 3, shown in Figure 11(h) and (i). The traditional FEM model did not predict the overturn of the boulder and truck override while the hybrid model did predict the override, results that could lead to false confidence in a barrier meeting P1 (a penetration distance of less than $1 \mathrm{~m}$ ) rating for a M30 impact based on FEM model prediction.

Figure 12 presents comparison between simulated boulder translational displacement (FEM and hybrid) versus time against test data taken from fiducial tracking of the boulder for Test 1 . Figure 13 shows the corresponding plot for boulder rotation. Both plots show a good agreement between the test and simulations. Figure 13 shows the FEM model accurately predicts boulder rotation; however, the hybrid model over-predicts the rotation in the late stages of impact. Nevertheless, Figures 12 and 13 demonstrate that LS-DYNA adequately captured overall dynamic response of Test 1 with minimal boulder and soil movement using two different modeling techniques embedded within the program.

Figure 14 presents comparisons of boulder translation parallel to the impact direction for Test 2 tracking fiducials from the field-scale test. Test 2 had moderate boulder and soil movement but the comparison of the FEM and hybrid simulations to the field data shows a good agreement. Both of the simulations over-predicted boulder translation. This may be due to using soil material properties taken from Test 1 even though this installation may have produced slightly different compaction 


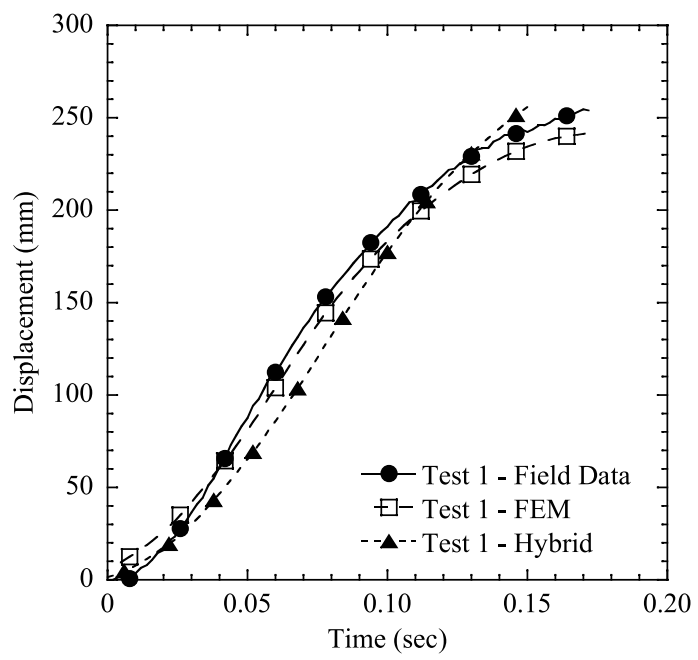

Figure 12. Center of gravity displacement for Test I: field data, FEM, and hybrid model.

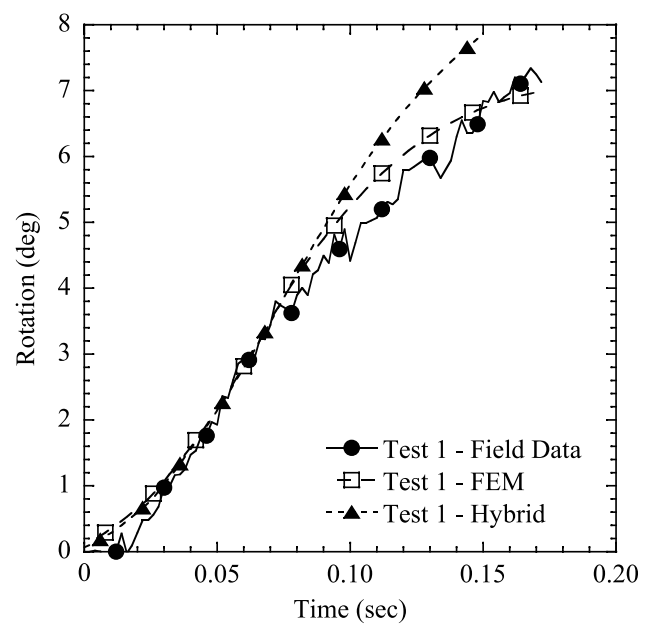

Figure 13. Center of gravity rotation for Test I: field data, FEM, and hybrid model.

levels for the AASHTO soil. Figure 15 shows the corresponding plot for boulder rotation. The FEM simulation was able to capture boulder rotation during impact. The hybrid simulation was able to capture the boulder rotation up to a certain point and then predicts a larger final rotation of the system. Regardless of minor installation differences that could have influenced material properties for the compacted AASHTO fill, both LS-DYNA simulations were able to adequately capture overall dynamic response under vehicular impact. 


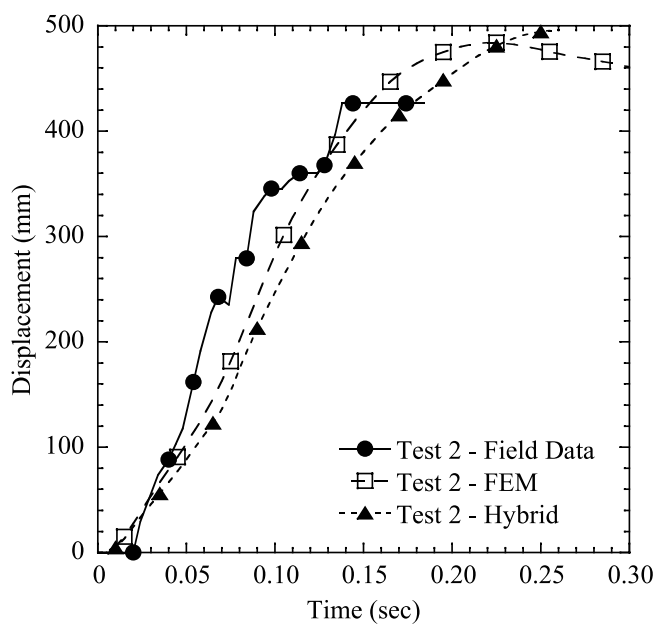

Figure 14. Center of gravity displacement for Test 2: field data, FEM, and hybrid model.

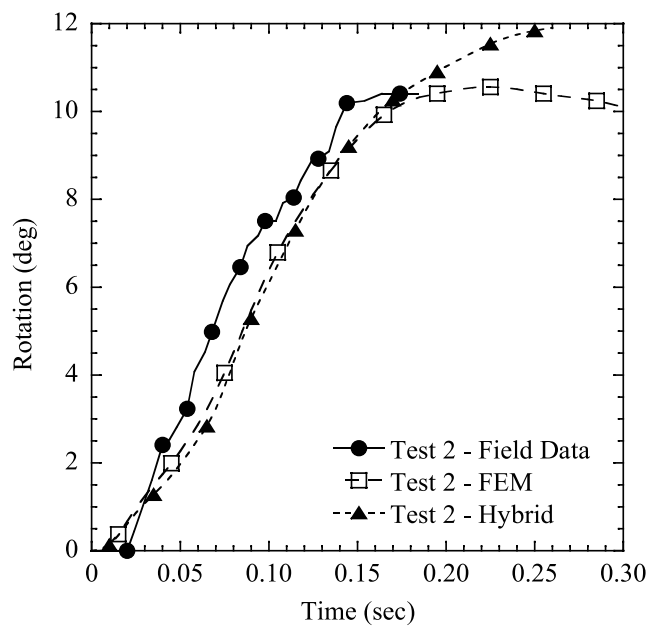

Figure 15. Center of gravity rotation for Test 2: field data, FEM, and hybrid model.

For Test 3, the high-speed cameras were not triggered prior to impact and, hence, high-speed video analysis was not available for boulder translation and rotation data. Instead, a qualitative analysis using images captured from a digital camera is presented as well as a comparison of the truck velocity from a low-resolution camera was used to compare Test 3 to FEM and hybrid numerical analyses. Figure 16 shows the qualitative comparison of the still images captured during Test 3 compared to the two LS-DYNA simulations. From Figure 16(b), it can be seen that the FEM simulation under-predicted boulder translation and rotation, as well as truck ramping. This is most likely due to FEM being a grid-based formulation that has difficultly simulating large 


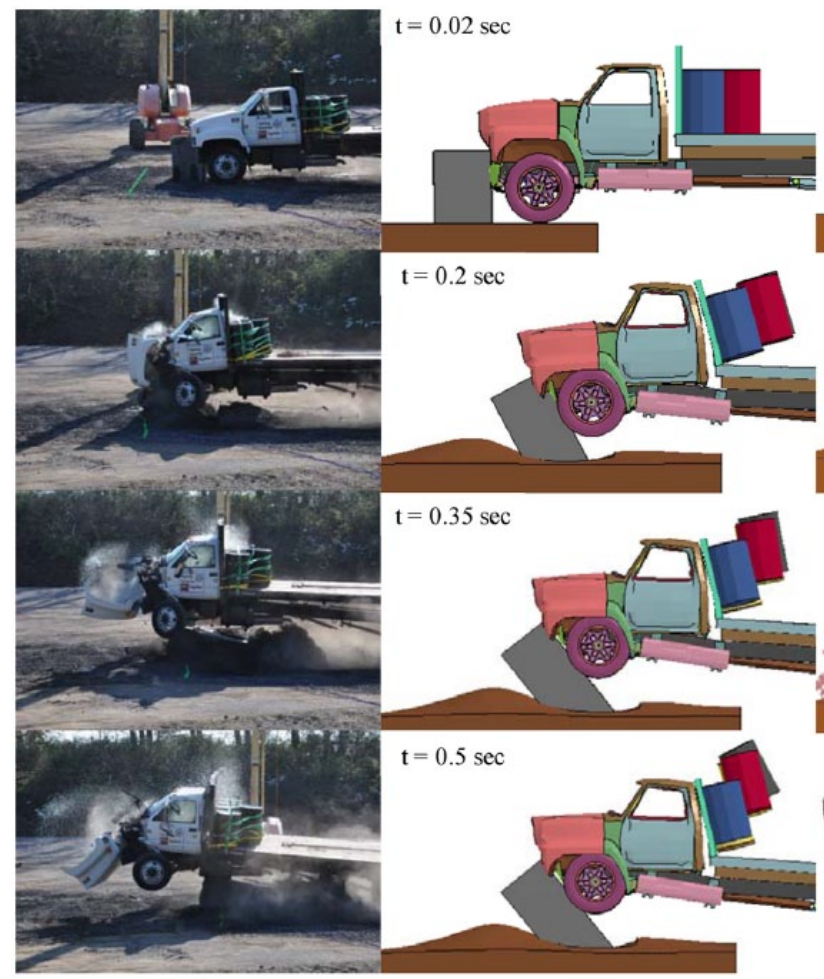

(a)

(b)

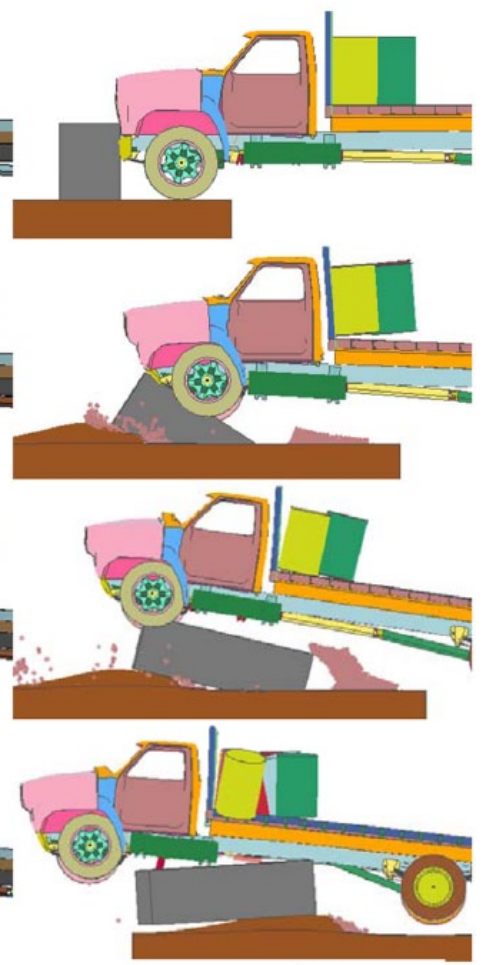

(c)

Figure 16. Comparison of digital camera images and LS-DYNA simulations at different simulation time steps: (a) Test 3; (b) FEM model; and (c) hybrid model.

deformations. On the other hand, the hybrid model predicts global response of the system, including boulder translation and rotation as well as truck ramping, relatively well as shown in Figure 16(c). The hybrid simulation did exhibit some boulder "sticking" underneath the truck which caused the boulder to drag after truck ramping. This "sticking" did not change the overall performance of the hybrid simulation.

Vehicular data were processed from a low-resolution hand-held camera for Test 3. The truck velocity in the direction of impact was analyzed and compared to the numerical simulations. Figure 17 shows a screenshot from the video analysis program. Photron FASTCAM Analysis software was used to analyze the video data (Photron, 2014) based on a dimensional scale, stationary point, and tracking point shown in Figure 17. The length of the boulder was used as the dimensional scale for each frame to determine the movement of the tracking point from one frame to the next. A stationary point was needed because the hand-held camera had a lot of movement throughout the impact. The stationary point was used to calibrate the tracking point, which was a point on the side door of the truck, to remove any artificial movements of the camera during the filming process. The same point on the truck was used to compare the truck velocity in the FEM and hybrid analyses. Figure 18 shows velocity versus time for the field-scale test, FEM simulation, and hybrid simulation. From this figure, it is clear that the FEM simulation is inaccurate and actually predicted the truck to stop 


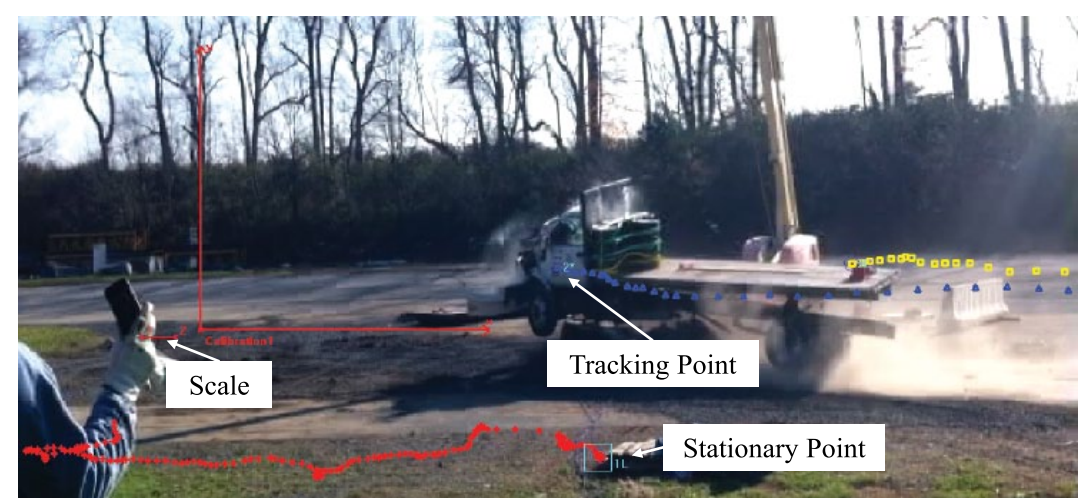

Figure 17. Video analysis of Test 3 showing length scale, stationary point, and tracking point.

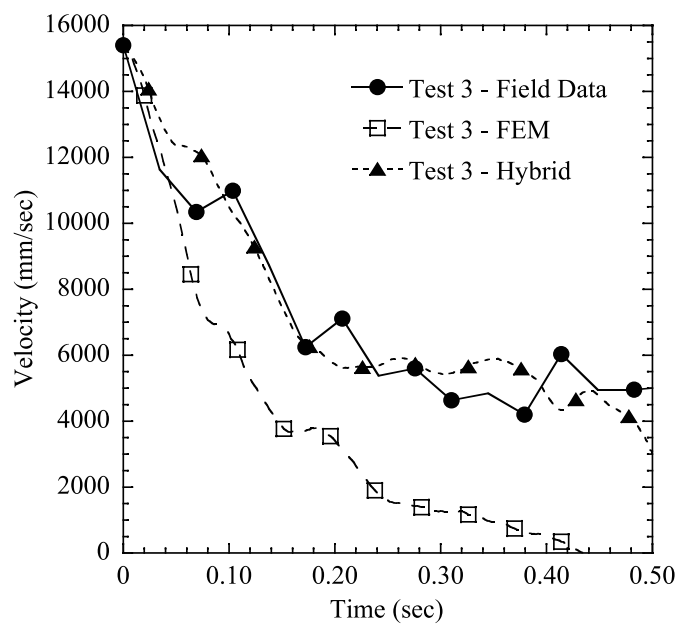

Figure 18. Truck velocity in direction of impact for Test 3: field data, FEM, and hybrid model.

at $0.42 \mathrm{~s}$ which was not the case in the field-scale test. The comparison between the field-scale test and the hybrid simulation shows good correlation. There is some error but this could be due to the quality of the video. For example, the truck shows an increase in velocity at certain points during impact which is physically impossible. Even with the poor quality video, the hybrid simulation predicts the truck behavior during impact.

From the above figures, it can be seen that there are advantages and disadvantages for both FEM and hybrid FEM-SPH modeling approaches. The obvious advantage of using a FEM formulation is its proven computational efficiency. However, if a model takes advantage of strategically placing more complex modeling techniques (i.e. SPH) in areas that are suspected to produce large deformations, a model can be computationally optimized while producing more accurate results. In all three tests, the hybrid approach was able to accurately predict the global response of the system under a vehicular impact while the FEM-only model for Test 3 failed to predict the response due to the large deformation near the area of impact. Another advantage of using a hybrid modeling 
approach is the ability to optimize the barriers, including size, weight, and embedment depth of the barrier, without the fear that the model is inaccurate. By optimizing the barrier, the economic benefits are tremendous. The cost of the boulder will decrease as well as the need to have special equipment onsite during the installation phase. These cost savings may be small relative to a single barrier but when hundreds are being installed around the perimeter of a critical asset that small savings add up.

\section{Conclusion}

This article presents three field-scale tests conducted and used to rate the performance of LVAR barrier systems against M30 impacts. Each barrier consisted of a single boulder embedded in compacted AASHTO aggregate. For each test, two LS-DYNA models were created to predict the global response of the system under vehicular impact. The first LS-DYNA model used traditional finite elements while the second model consisted of a hybrid FEM-SPH approach. Test 1 resulted in minimal boulder and soil movement; Test 2 resulted in moderate boulder and soil movement; and Test 3 resulted in excessive boulder rotation, large soil deformations, and truck override. For Tests 1 and 2, both the traditional FEM approach and the hybrid FEM-SPH approach were able to accurately match data collected from the field tests. However, for Test 3, the traditional FEM approach was not able to accurately predict global response of the system under vehicular impact. The hybrid approach was able to capture global response of the system including boulder rotation, soil upheaval, and truck override. This research suggests that a hybrid FEM-SPH approach is advantageous in simulating the field performance of embedded structures under impact loading involving large deformation of soil.

Several parameters were determined to help accurately predict global response of the system when implementing a hybrid FEM-SPH modeling approach. First, there needs to be at least five SPH particles per finite element length at all FEM-SPH boundaries. Second, the extent of nearfield SPH soil domain needs to be proportional to $1 / 2$ the embedment depth of the boulder for adequate computational efficiency and accuracy.

\section{Acknowledgements}

The authors would like to thank the United States Department of State and the Larson Transportation Institute at The Pennsylvania State University for their continuing support of this research. The opinions, findings, and conclusions stated herein are those of the authors and do not necessarily reflect those of the United States Department of State.

\section{Declaration of conflicting interests}

The author(s) declared no potential conflicts of interest with respect to the research, authorship, and/or publication of this article.

\section{Funding}

The author(s) disclosed receipt of the following financial support for the research, authorship, and/or publication of this article: This article was funded by a grant from the United States Department of State.

\section{References}

Aktay L, Johnson AF and Kröplin BH (2005) Combined FEM/meshfree SPH method for impact damage prediction of composite sandwich panels. In: ECCOMAS (European Community on Computational Methods in Applied Sciences) thematic conference on meshless methods, Lisbon, Portugal, 11-14 July 2005. 
American Society for Testing and Materials (ASTM) (2007) F2656-F265-7: standard test method for vehicle crash testing of perimeter barriers.

American Society for Testing and Materials (ASTM) (2015) D6939-D693-5: test method for in-place density and water content of soil and soil-aggregate by nuclear methods (shallow depth).

Asadollahi Pajouh M, Lim SG, Mirdamadi A, et al. (2014) Full-scale test and numerical simulation of a truck impacting a group of side by side piles. In: Geo-congress 2014: technical papers, Atlanta, GA, 23-26 February 2014.

Bathurst RJ and Simac M (1994) Geosynthetic reinforced segmental retaining wall structures in North America. In: Proceedings of the fifth international geosynthetics conference (SEAC-IGA), Singapore, 5-9 September 1994, pp. 29-54.

Beal T, Van Dorsselaer N and Lapoujade V (2013) A contribution to validation of SPH new features. In: 9th European LS-DYNA conference, Manchester, UK, 2-4 June 2013.

Belytschko T, Liu WK and Moran B (2000) Nonlinear Finite Elements for Continua and Structures. New York: John Wiley \& Sons.

Bojanowski C (2014) Numerical modeling of large deformations in soil structure interaction problems using FE, EFG, SPH and MM-ALE formulations. Archive of Applied Mechanics 84: 743-755.

Bojanowski C and Kulak RF (2010) Comparison of Lagrangian, SPH and MM-ALE approaches for modeling large deformations in soil. In: 11th international LS-DYNA users conference, Detriot, MI, 6-8 June 2010.

Bui H, Fukgawa R, Sako K, et al. (2008) Lagrangian mesh-free particle method (SPH) for large deformation and post-failure flows of geomaterial using elastic-plastic soil constitutive model. International Journal for Numerical and Analytical Methods in Geomechanics 32(12): 1537-1570.

Chen W and Qiu T (2012) Numerical simulations for large deformation of granular materials using smoothed particle hydrodynamics method. International Journal of Geomechanics 12(2): 127-135.

Chen W and Qiu T (2014) Simulation of earthquake-induced slope deformation using SPH method. International Journal for Numerical and Analytical Methods in Geomechanics 38: 297-330.

Coldspring Quarry (2014) Rockville White granite material properties. Available at: http://www.coldspringusa. com/building-materials/products-colors-and-finishes/granite/rockville-white/ (accessed 7 January 2014).

Finn WDL, Yogendrakumar M and Yoshida N (1986) TARA-3: A Program to Compute the Response of 2-D Embankment and Soil-Structure Interaction Systems to Seismic Loading. Vancouver, BC, Canada: Department of Civil Engineering, University of British Columbia.

Gere J and Timoshenko S (1984) Mechanics of Materials. Monterey, CA: Brooks/Cole Engineering Division, p. 762.

Gingold RA and Monaghan JJ (1977) Smoothed particle hydrodynamics: theory and application to nonspherical stars. Monthly Notices of the Royal Astronomical Society 181(2): 375-389.

Hallquist JO (2013) LS-DYNA Keyword User's Manual (Version R7.0). Livermore, CA: Livermore Software Technology Corporation.

Hughes TJR, Liu WK and Zimmerman TK (1981) Lagrangian-Eulerian finite element formulation for incompressible viscous flows. Computational Methods in Applied Mechanics and Engineering 29: 329-349.

International Society for Rock Mechanics (ISRM) (2007) The complete ISRM suggested methods for rock characterization, testing and monitoring: 1974-2006. In: Ulusay R (ed) Commission on Testing Methods, International Society for Rock Mechanics. Ankara, Turkey: ISRM Turkish National Group, p. 628.

Jackson KE and Fuchs YT (2008) Comparison of ALE and SPH simulations of vertical drop tests of a composite fuselage section into water. In: 10th international LS-DYNA users conference, Detroit, MI, 8-10 June 2008.

Jankowiak T and Lodygowski T (2013) Smoothed particle hydrodynamics versus finite element method for blast impact. Bulletin of the Polish Academy of Sciences Technical Sciences 71(1): 111-121.

Johnson G (1994) Linking of Lagrangian particle methods to standard finite element methods for high velocity impact computations. Nuclear Engineering and Design 150: 265-274.

Keske MP, Brown AA, Brennan SN, et al. (2015) Low-order modeling of vehicle impacts upon boulders embedded in cohesionless soil. International Journal of Impact Engineering 75: 88-99.

Khoei AR and Lewis RW (1999) Adaptive finite element remeshing in a large deformation analysis of metal powder forming. International Journal of Numerical Methods for Engineering 45: 801-820. 
Kulak RF and Schwer L (2012) Effect of soil material models on SPH simulations for soil-structure interaction. In: 12th international LS-DYNA users conference, Detroit, MI, 3-5 June 2012.

Liu GR and Liu MB (2003) Smoothed Particle Hydrodynamics: A Meshfree Particle Method. Singapore: World Scientific.

Livermore Software Technology Company (LSTC) (2006) LS-DYNA Theory Manual. Livermore, CA: LSTC.

Lucy L (1977) A numerical approach to testing the fission hypothesis. The Astronomical Journal 82(12): $1013-1024$.

Mohan P, Marzougui D and Kan S (2003) Validation of a single unit truck model for roadside hardware impacts. NCAC 2003-W-01. Ashburn, VA: National Crash Analysis Center (NCAC).

Mohotti D, Raman S, Ngo T, et al. (2015) Use of coupled smooth-particle hydrodynamics/lagrangian method in the simulation of deformable projectile penetration. International Journal of Protective Structures 6(3): 419-437.

National Crash Analysis Center (NCAC) (2008) Finite element model archive: ford single unit truck, reduced model. Available at: http://www.ncac.gwu.edu/vml/models.html (accessed 3 September 2013).

Photron (2014) Photron FASTCAM Analysis (PFA) (Version 1.2.0). Tokyo: Photron.

Reese L, Qiu T, Linzell D, et al. (2012) Development of landscape vehicular anti-ram systems through computational and experimental methods. In: Proceedings of the 83rd shock and vibration symposium, New Orleans, LA, 4-9 November 2012.

Reese L, Qiu T, Linzell D, et al. (2014) Field tests and numerical modeling of vehicle impacts on a boulder embedded in compacted fill. International Journal of Protective Structures 5(4): 435-451.

Ren Z and Vesenjak M (2005) Computational and experimental crash analysis of the road safety barrier. Engineering Failure Analysis 12: 963-973.

Rock of Ages Quarry (2015) American Black granite material properties. Available at: http://www.rockofages.com/en/quarry/materials/granite-colors/ (accessed 2 April 2015).

Sakakibara T, Tsuda T and Ohtagaki R (2008) A study of quasi-static problem by SPH method. In: 10th international LS-DYNA users conference, Detroit, MI, 8-10 June 2008.

Schwer LE (2009) Aluminum plate perforation: a comparative case study using Lagrange with erosion, multi-material ALE, and smooth particle hydrodynamics. In: 7th European LS-DYNA conference, Salzburg, Austria, 14-15 May 2009.

Stalker Traffic Technologies (2014) Dashboard PC Application and Speed Sensor User Manual for Stationary, Speedometer and Traffic Models. Plano, TX: Stalker Traffic Technologies.

Swaddiwudhipong S, Islam M and Liu Z (2010) High velocity penetration/perforation using coupled smooth particle hydrodynamics-finite element method. International Journal of Protective Structures 1(4): 489-506.

Thiyahuddin I, Gu YT, Thambiratnam DP, et al. (2012) Impact \& energy absorption of road safety barriers by coupled SPH/FEM. International Journal of Protective Structures 3(3): 257-274.

$\mathrm{Wu} \mathrm{W}$ and Thomson R (2007) A study of the interaction between a guardrail post and soil during quasi-static and dynamic loading. International Journal of Impact Engineering 34: 883-898.

Wyllie D and Mah C (2004) Rock Slope Engineering: Civil and Mining. New York: Spon Press, p. 456.

Xia K, Dai F and Chen R (2011) Split Hopkinson pressure bar tests of rocks: advances in experimental techniques and applications to rock strength and fracture. In: Zhou Y and Zhao J (eds) Advances in Rock Dynamics and Applications. London: CRC Press, pp. 35-77.

$\mathrm{Xu} \mathrm{J}$ and Wang $\mathrm{J}$ (2014) Interaction methods for the SPH parts (multiphase flows, solid bodies) in LS-DYNA. In: 13th international LS-DYNA users conference, Detroit, MI, 8-10 June 2014.

Zhou Y, Reese L, Qiu T, et al. (2016) Field test and numerical modeling of vehicle impact on a boulder with impact-induced fractures. International Journal of Protective Structures 7(1): 3-17. 